\title{
Changes in Urine by Test Strips after High-Intensity Intermittent Session: Can be a Means for Training Control
}

\author{
Aldo Alfonso Vasquez Bonilla* \\ Department of Physical Education, University Pedagogical National Francisco Morazán, San Pedro Sula, Honduras
}

Submission: April 02, 2018; Published: April 18, 2018

*Corresponding author: Aldo Alfonso Vasquez Bonilla, Department of Physical Education, University Pedagogical National Francisco Morazán, San Pedro Sula, Honduras, Email: aldovasquez1994@hotmail.com

\begin{abstract}
The objective of the study was to measure the changes in urine with strips test after a high-intensity intermittent session and how it is relations to fatigue. The sample was 10 physically active university students, the Sprint intensity-training (SIT) session consisted of performing $20^{\prime}$ with 12 "of sprint pedaling (100-140 rpm) with a load that is around $80-90 \%$ of the peak heart rate and 18 "of a low intensity pedaling performed at $40 \mathrm{rpm}$. Urine was measured pre-session and 24 hours after the session, oxygen consumption in a maximum incremental test in a cycle ergo meter and test Wingate. A statistical analysis was performed with the Kruskal-Wallis tests for relations variables and Spear mean correlation. There was a small increase in leukocytes $(\mathrm{p}=0.04)$ and a decrease in $\mathrm{pH}(\mathrm{p}=0.04)$ after the SIT session, there was also an inverse correlation of the rating of perceived exertion and level physical condition with the increase in leukocytes $(r=-0.56 / p=0.03)$ and $(r=-0.50 /$ $\mathrm{p}=0.03)$ and decrease in $\mathrm{pH}$ with oxygen consumption $(\mathrm{r}=-0.77 / \mathrm{p}=0.00)$. The measurement of metabolites in urine by strips test could be a means to control training, although the results are unclear, therefore, it is recommended to make a longitudinal study with assessments in fatigue and recovery.
\end{abstract}

Keywords: Fatigue; Urine strips; Ph; Leukocytes

Abbreviations: SIT: Sprint Intensity Training; UPNFM: University Pedagogical National Francisco Morazán; RPE: Rating of Perceived Exertion; FR: Free Radicals; NADPH: Nicotinamide Adenine Dinucleotide Phosphate; NOS: Nitric Oxide Synthase

\section{Introduction}

The control of the training is necessary in the planning by the coaches, in order to understand the metabolic process that produces the high-intensity training in the fatigue of athletes [1] since it could be affected the performance 24, 48 and 72 hours later [2] when a good recovery after a high-intensity training has not been obtained. There are many ways to assess fatigue and its recovery through different blood tests, physical tests and psychological tests [3]. The urine test strips have been valid for reporting urinary tract infections [4], the test strips have the distinction of being easily accessible for sampling (it is not painful compared to obtaining them a blood sample) and it is relatively inexpensive to perform this control [5]. One study indicated that medical personnel can use this information to maximize the athletic performance of their equipment and minimize the health risks related to heat and dehydration of athletes [6].
The objective of this study was to analyze the measurement of the load at the metabolic level after a high-intensity interval exercise and correlate it with the acute fatigue caused by the exercise.

\section{Methodology \\ Participants}

The samples in the study were 10 subjects (four male and six female) university students, who practiced moderate regular sports practice. They signed an informed consent in writing of the protocol of action prior to conducting the tests. For this study the principles of declaration of Helsinski were followed. Was ethics approved by the group of professors of the National Pedagogical University Francisco Morazán (UPNFM). The characteristics of the sample of the 10 experimental subjects are shown in Table 1. 
Table 1: Anthropometric and physical condition characteristics of the participants.

\begin{tabular}{|c|c|}
\hline Variables & Media \pm SD \\
\hline \multicolumn{2}{|c|}{ Anthropometric Characteristics } \\
\hline Age (years) & $26 \pm 2$ \\
\hline Height (m) & $1.59 \pm 0.07$ \\
\hline Weight (kg) & $60.0 \pm 10.2$ \\
\hline BMI $\left(\mathrm{kg} / \mathrm{h}^{\wedge} 2\right)$ & $23.3 \pm 2.5$ \\
\hline \multicolumn{2}{|c|}{ Physical Condition } \\
\hline Power peak (watts) & $182 \pm 40.5$ \\
\hline Maximum oxygen consumption $(\mathrm{kg} / \mathrm{ml} / \mathrm{min})$ & $44.9 \pm 5.3$ \\
\hline Maximum heart rate (ppm) & $183 \pm 12.4$ \\
\hline Heart rate Rest (ppm) & $65.2 \pm 8.6$ \\
\hline
\end{tabular}

\section{Procedures}

Indirect Maximum Oxygen Consumption: The participants performed a warm-up of $5 \mathrm{~min}$ at $35 \mathrm{~W}$, the maximum incremental test was performed a cycle ergometer (ergometrics 900, ergoline Germany) the start protocol at 50W, the resistance was increased by $25 \mathrm{~W}$ every 3 minutes until exhaustion or when the pedaling cadence fell below 50rpm. Oxygen consumption was measured with the modified ASCM formula vo2 $\mathrm{max}=(($ final load $/$ weight $)$ $\mathrm{x} 10,483+7)[7]$.

Sprint High-Training Session: Participants in a Sprint intensity-training (SIT) session performed on a cycle ergometer for 20 minutes performing 12" sprint pedaling (100-140rpm) with a load that is around $80-90 \%$ of the frequency peak heart rate was controlled with a heart rate monitor ( Polar $\rightarrow$ S810i, USA), to these 12 " of sprint, followed by 18 " of a low intensity pedaling performed at $40 \mathrm{rpm}$, that is, it is a pause slightly 'active' With which, we have 12 " +18 " forming a block of 30 ", and taking in 40 blocks of 30 " for 20 minutes. A $5^{\prime}$ warm-up is also carried out with light muscle stretches and a return to the also 5' calm with stretching exercises. This methodology is found in the study of Heydari M et al. [8].

Wingate Test: The Wingate test theoretically allows, according to Vandewalle $\mathrm{H}$ et al. [9], the measurement of the maximum anaerobic power (peak power), the total amount of work developed (anaerobic capacity) and the study of the power decrease during the test (fatigue index). In this study the Wingate test was developed on a cycle ergometer (ergometrics 900, ergoline Germany) for 30 seconds, against a constant resistance (0.075 kilograms per kilogram of body weight) according to international considerations. Prior to the beginning of the assessment, the height of the chair and the straps were adjusted according to the length of the lower limbs of the patient, a verbal signal was given (beginning), a countdown and a continuous verbal motivation to ensure the maximum manifestation of physical capacity. The Rating of Perceived Exertion (RPE) was also assessed 15 minutes after the test [10].

Analysis of Urine Strips: Test urine strips (Duos 10, manufacturer: SBZX) are used, which contain specific indicators, reagents and buffers for the determination of $\mathrm{pH}$, density, leukocytes, nitrites, protein, glucose, ketones, urobilinogen, bilirubin, blood. The strip will change color according to the substances present in the urine, and will be read at the time indicated by comparing it with the color chart provided by the manufacturer. Before introducing the test strip the urine, the sample must be homogenized and collected in a clean and dry container. This was done within an hour to avoid possible changes in $\mathrm{pH}$. The strip is inserted into the bottle for 120 minutes. Seconds to ensure that all parameters are read accurately (Figure 1). 


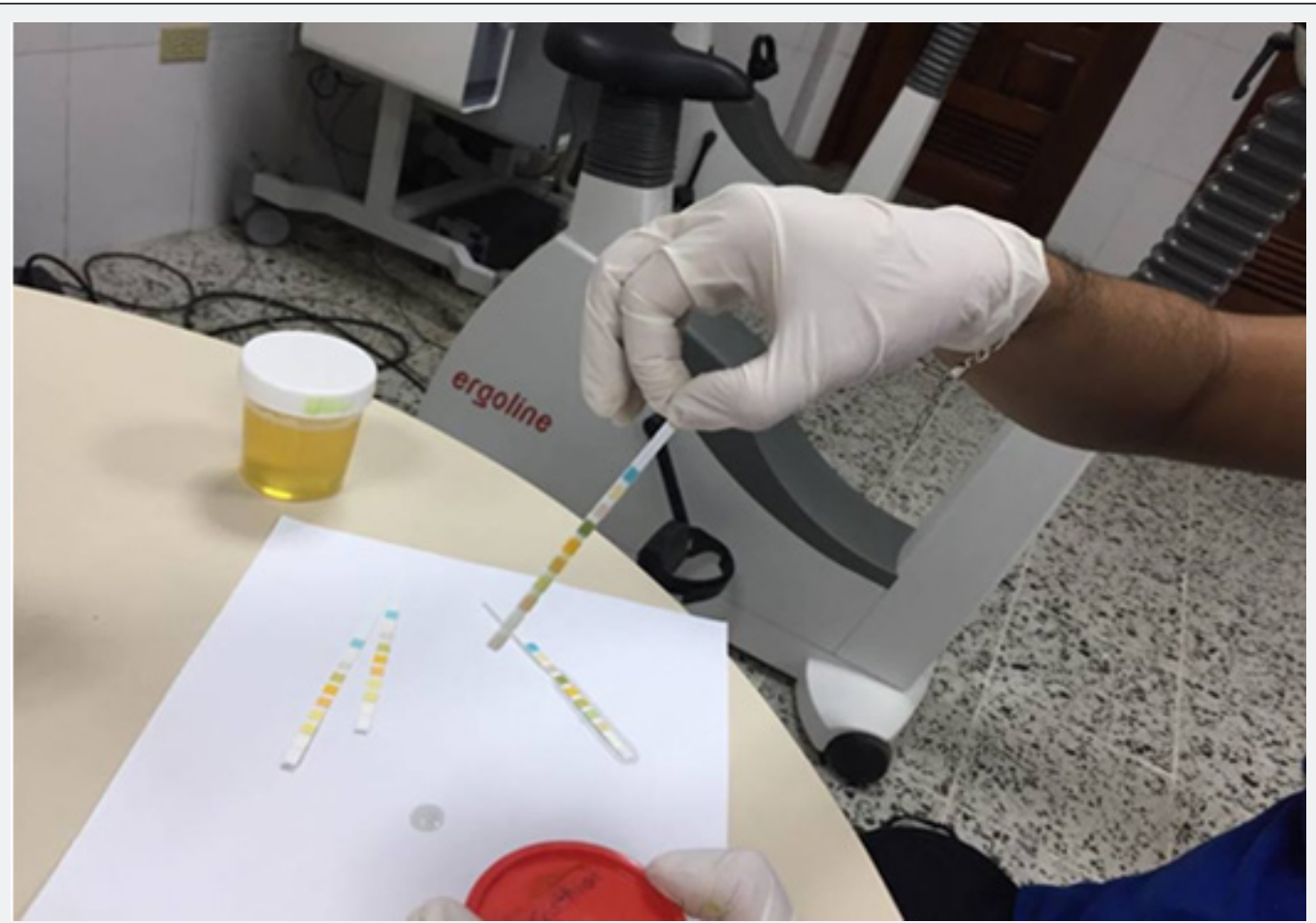

Figure 1: Analysis of urine using the strips test, exercise physiology laboratory (UPNFM-San Pedro Sula).

Statistical Analysis: First a non-parametric Kruskal-Wallis test was performed for samples performed in the comparison of the pre and post 24 hours, and then a correlation analysis was applied with the coefficient Spear mean between variable of urine, RPE, oxygen consumption and \%fatigue. The level of statistical significance was established at $\mathrm{p}$ value $<0.05$ with confidence intervals (95\%). The analyzes were carried out using SPSS for Windows (SPSS v.22.0, Chicago, IL, USA).

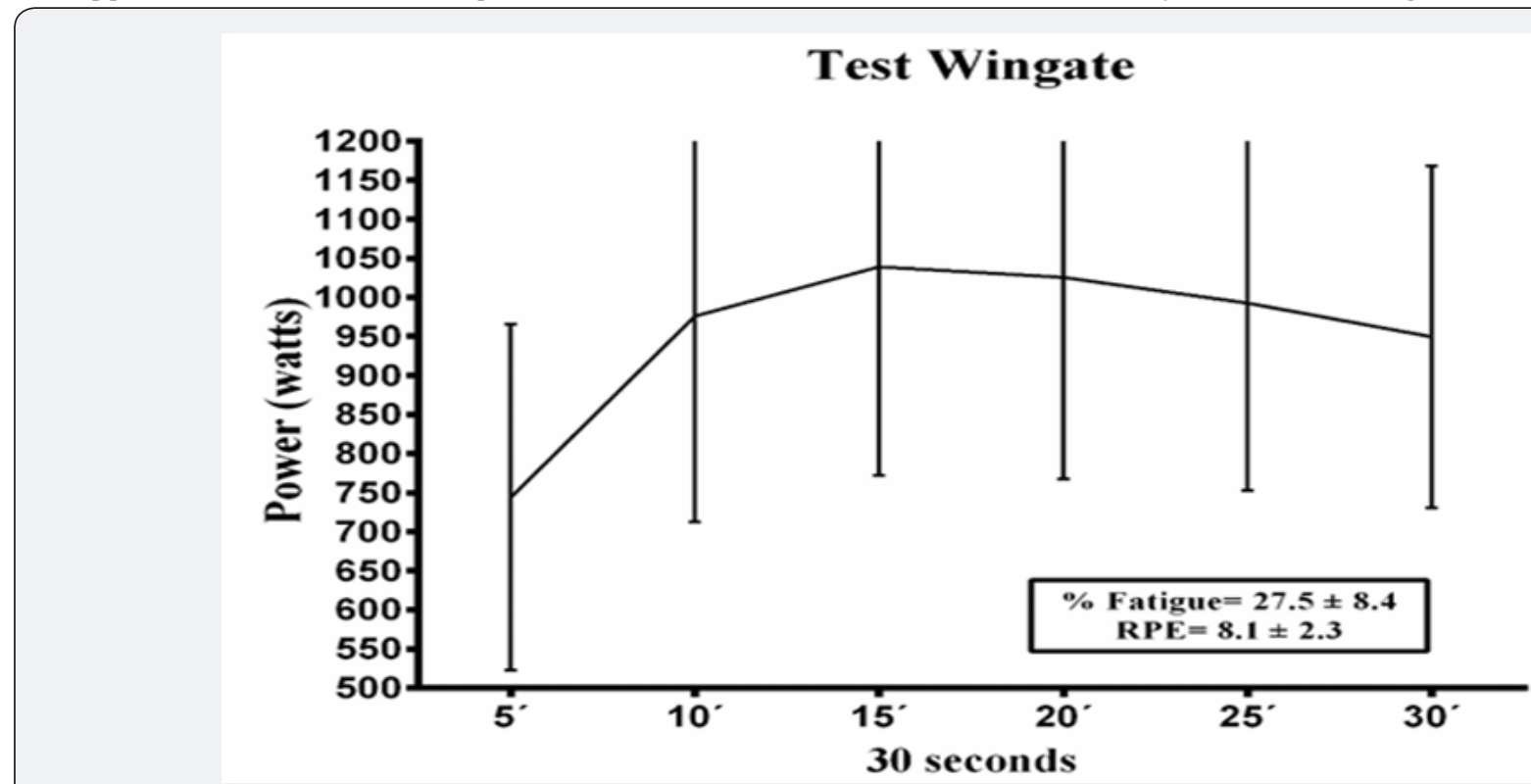

Figure 2: Test Wingate and Rating of Perceived Exertion, after a (SIT) session. 
Journal of Physical Fitness, Medicine \& Treatment in Sports

Table 2: Individual results of the measurement of metabolites through urine strips 10 parameters in physically active subjects.

\begin{tabular}{|c|c|c|c|c|c|c|c|c|c|c|c|}
\hline \multicolumn{2}{|c|}{ Particpants } & \multirow{2}{*}{$\begin{array}{c}\text { Leukocytes } \\
\text { Negative }\end{array}$} & \multirow{2}{*}{$\begin{array}{l}\text { Nitrites } \\
\text { Negative }\end{array}$} & \multirow{2}{*}{$\begin{array}{c}\text { Urobilinogen } \\
\text { Normal }\end{array}$} & \multirow{2}{*}{$\begin{array}{l}\text { Protein } \\
\text { Negative }\end{array}$} & \multirow{2}{*}{$\begin{array}{c}\text { pH } \\
6\end{array}$} & \multirow{2}{*}{$\begin{array}{l}\text { Blood } \\
2+80\end{array}$} & \multirow{2}{*}{$\begin{array}{c}\text { Density } \\
1,015\end{array}$} & \multirow{2}{*}{$\begin{array}{l}\text { Ketones } \\
\text { Negative }\end{array}$} & \multirow{2}{*}{$\begin{array}{l}\text { Bilirubin } \\
\text { Negative }\end{array}$} & \multirow{2}{*}{$\begin{array}{l}\text { Glucose } \\
\text { Negative }\end{array}$} \\
\hline & Pre & & & & & & & & & & \\
\hline Subject 1 & $\begin{array}{c}>24 \\
\text { hours }\end{array}$ & Negative & Negative & Normal & Negative & 6 & Negative & 1,025 & Negative & Negative & Negative \\
\hline \multirow{2}{*}{ Subject 2} & Pre & Negative & Negative & Normal & Negative & 6 & Negative & 1,025 & Negative & Negative & Negative \\
\hline & $\begin{array}{c}>24 \\
\text { hours }\end{array}$ & 70 & Negative & Normal & Negative & 6 & Negative & 1,03 & Negative & Negative & Negative \\
\hline \multirow{2}{*}{ Subject 3} & Pre & Negative & Negative & Normal & Negative & 6 & Negative & 1 & Negative & Negative & Negative \\
\hline & $\begin{array}{c}>24 \\
\text { hours }\end{array}$ & 70 & Negative & Normal & Negative & 6 & Negative & 1 & Negative & Negative & Negative \\
\hline \multirow{2}{*}{ Subject 4} & Pre & Negative & Negative & Normal & Negative & 6 & Negative & 1,03 & Negative & Negative & Negative \\
\hline & $\begin{array}{c}>24 \\
\text { hours }\end{array}$ & Negative & Negative & Normal & Negative & 6 & Negative & 1,02 & Negative & Negative & Negative \\
\hline \multirow{2}{*}{ Subject 5} & Pre & Negative & Negative & Normal & Negative & 6 & Negative & 1,02 & Negative & Negative & Negative \\
\hline & $\begin{array}{c}>24 \\
\text { hours }\end{array}$ & Negative & Negative & Normal & Negative & 5 & Negative & 1,025 & Negative & Negative & Negative \\
\hline \multirow{2}{*}{ Subject 6} & Pre & Negative & Negative & Normal & Negative & 7 & Negative & 1,015 & Negative & Negative & Negative \\
\hline & $\begin{array}{c}>24 \\
\text { hours }\end{array}$ & 70 & Negative & Normal & Negative & 6 & Negative & 1,025 & Negative & Negative & Negative \\
\hline \multirow{2}{*}{ Subject 7} & Pre & Negative & Negative & Normal & Negative & 6 & Negative & 1,02 & Negative & Negative & Negative \\
\hline & $\begin{array}{c}>24 \\
\text { hours }\end{array}$ & Negative & Negative & Normal & Negative & 6 & Negative & 1,025 & Negative & Negative & Negative \\
\hline \multirow{2}{*}{ Subject 8} & Pre & Negative & Negative & Normal & Negative & 6 & Negative & 1,03 & Negative & Negative & Negative \\
\hline & $\begin{array}{c}>24 \\
\text { hours }\end{array}$ & Negative & Negative & Normal & Negative & 6 & Negative & 1,02 & Negative & Negative & Negative \\
\hline \multirow{2}{*}{ Subject 9} & Pre & Negative & Negative & Normal & Negative & 6 & Negative & 1,025 & Negative & Negative & Negative \\
\hline & $\begin{array}{c}>24 \\
\text { hours }\end{array}$ & 70 & Negative & Normal & Negative & 6 & Negative & 1,025 & Negative & Negative & Negative \\
\hline \multirow{2}{*}{$\begin{array}{c}\text { Subject } \\
10\end{array}$} & Pre & Negative & Negative & Normal & Negative & 7 & Negative & 1,025 & Negative & Negative & Negative \\
\hline & $\begin{array}{c}>24 \\
\text { hours }\end{array}$ & Negative & Negative & Normal & Negative & 6 & Negative & 1,03 & Negative & Negative & Negative \\
\hline \multicolumn{2}{|c|}{$* \mathrm{P}$ Value $<0.05$} & $0.046^{*}$ & 1 & 1 & 1 & $0.048^{*}$ & 1 & 0.436 & 1 & 1 & 1 \\
\hline
\end{tabular}

\section{${ }^{*} \mathrm{P}$ value 0.05 statistically significant}

Table 2 presents the individual results of each pre-training subject and 24 hours later to observe changes in urine metabolites. An increase in leukocytes +70 can be observed in 4 subjects ( $\mathrm{p}$ value $=0.04$ ) and a decrease in $\mathrm{pH}$ in 5 subjects ( $\mathrm{p}$ value $=0.04)$. There are changes in the density of urine, but they are not significant. Figure 2 represents the power values expressed with the mean \pm standard deviation obtained in the wingate test, the mean fatigue $\%$ values and the rating of perceived exertion are shown after the SIT. There is no clear decrease in the power values. \%Fatigue is very low during this test. 
Table 3 presents existence correlations between metabolites of urine, oxygen consumption (level of physical condition) and $\%$ fatigue. A moderate negative correlation can be observed between the leukocytes and the RPE ( $p$ value $=0.03$ ) and level of physical condition ( $\mathrm{p}$ value $=0.03$ ), the $\mathrm{pH}$ has a high negative correlation with the level of physical condition ( $p$ value $=0.00$ ) There is also moderate positive correlation between fatigue $\%$ and RPE ( $\mathrm{p}$ value $=0.02$ ), $\mathrm{pH}$ also correlates with urine density $(\mathrm{p}$ value $=0.00)$.

Table 3: Correlations between Fatigue\%, Effort perception, Oxygen consumption and Urine parameters.

\begin{tabular}{|c|c|c|c|c|c|c|}
\hline Variables & $\%$ Fatigue & RPE & $\mathrm{Vo}_{2} \max (\mathrm{ml} / \mathrm{kg} / \mathrm{min})$ & Leukocytes & pH & Density \\
\hline$\%$ de fatigue & 1 & $0.577^{*}$ & -0.109 & $-0,218$ & 0,169 & $-0,085$ \\
\hline RPE & $0.577^{*}$ & 1 & -0.113 & $-0.563^{*}$ & 0.29 & 0.116 \\
\hline Vo2max (ml/kg/min) & -0.109 & -0.113 & 1 & $-0.500 *$ & $-0.775^{* *}$ & -0.194 \\
\hline Leukocytes & -0.218 & $-0.563^{*}$ & $-0.500^{*}$ & 1 & 0.029 & -0.389 \\
\hline $\mathrm{pH}$ & 0.169 & 0.29 & $-0.775^{* *}$ & 0.029 & 1 & $-0.889 * *$ \\
\hline Density & -0.085 & 0.116 & -0.194 & -0.389 & $-0.889^{* *}$ & 1 \\
\hline
\end{tabular}

${ }^{*} p$ value 0.05 and ${ }^{* *} p$ value 0.01 statistically significant.

\section{Discussion}

This study gives us a new vision to use the urine strips test for correlate with fatigue in athletes.

\section{Physiology of Leukocytes in Urine and High-Intensity Exercise}

High intensity exercise causes a de-balance in the performance of reactive oxygen species (ROS)/ free radicals (FR). The cellular sources of ROS/ FR consist of the mitochondrial electron transport chain, nicotinamide adenine dinucleotide phosphate (NADPH) oxidase, xanthine oxidase, peroxisomes, and nitric oxide synthase (NOS). The immune system is unique in ROS/ FR production by leukocytes that make up the immune system provides cellular protection against infectious agents that initiate inflammatory responses [11], this acute immune response can occur after muscle damage [12]. The activation of the immune system triggers macrophages, neutrophils, lymphocytes and other phagocytic cells to sites of inflammation, during this process, these phagocytic cells generate ROS and FR, which can be used for cellular signaling, elimination of infectious organisms, induction of apoptosis and the stimulation of antioxidant repair processes and physical activity (both aerobic and anaerobic) is accompanied by an increase in ROS/FR production [13]. In addition, during the post-exercise recovery period, the acute immune response resembles that of infection and inflammation [14]. The immune response during recovery has also been shown to depend on the intensity and duration of exercise [11]. The increase in oxidative stress seen during exercise and the subsequent elevation in acute immune response during exercise recovery provides a unique opportunity to study the relationship between stress and immunity.

\section{Physiology of pH and Urine}

In the presence of acid urine (pH less than 5.6), myoglobin dissociates into globulin and hematin. It has been shown that hematin infusions cause more constant decreases in the glomerular filtration rate than myoglobin. The toxic effect of hematin at a cellular level has been attributed to the production of heme iron from free hydroxyl radicals. In urine below $\mathrm{pH}$ 5.0, the solubility of myoglobin decreases dramatically. In this $\mathrm{pH}$ range, the myoglobin formation and the percentage of myoglobin retained in the tubules increase [15]. In this study, there were no pH changes outside the normal ranges.

\section{Limitations and Recommendations}

Among the main limitations are:

a) that a blood evaluation was not carried out parallel to the response in urine,

b) the sample should be more specific for sport and sex,

c) food and quality sleep were not controlled

d) It is necessary to make a validation study of the urine strips test in the metabolite assessment.

It is recommended to extend the study with more variables used in the assessment of fatigue: As blood markers, heart rate, countermovement jump and psychological wellness scale [3]. A more in-depth study of other variables that affect muscle damage during exercise should also be carried out, since the reason for changes in leukocytes in urine after a high intensity session is not explained. A controlled study should be conducted in population of elite athletes.

\section{Conclusion}

The measurement of metabolites in the urine by strips test can be a means to control training, specifically there are associated changes in leukocytes and $\mathrm{pH}$ after a high-intensity intermittent session, and therefore it is recommended to make a longitudinal study with evaluations in a state of fatigue and recovery.

\section{References}

1. Wiewelhove T, Raeder C, Meyer T, Kellmann M, Pfeiffer M, et al. (2015) Markers for routine assessment of fatigue and recovery in male and 
female team sport athletes during high-intensity interval training. PloS one 10(10): e0139801.

2. Dawson E, George K, Shave R, Whyte G, Ball D (2003) Does the human heart fatigue subsequent to prolonged exercise? Sports Medicine 33(5): 365-380.

3. Thorpe RT, Atkinson G, Drust B, Gregson W (2017) Monitoring Fatigue Status in Elite Team-Sport Athletes: Implications for Practice. International journal of sports physiology and performance 12(Suppl 2): 227-234.

4. Winkens RA, Leffers P, Trienekens TA, Stobberingh EE (1995) The validity of urine examination for urinary tract infections in daily practice. Family Practice 12(3): 290-293.

5. Lapo L, Elizabeth M (2016) Alteraciones en el examen físico químico en la orina de un deportista. Unidad Académica de Ciencias Químicas y de la Salud, Machala, Ecuador, USA, p. 18.

6. Oppliger RA, Bartok C (2002) Hydration testing of athletes. Sports Medicine 32(15): 959-971.

7. Silva CG, Araújo CGS (2015) Sex-specific equations to estimate maximum oxygen uptake in cycle ergometry. Arquivos brasileiros de cardiología 105(4): 381-389.

8. Heydari M, Freund J, Boutcher SH (2012) The effect of high-intensity intermittent exercise on body composition of overweight young males. Journal of obesity, p. 8.
9. Vandewalle H, Peres G, Heller J, Monod H (1985) All out anaerobic capacity tests on cycle ergometers. European journal of applied physiology and occupational physiology 54(2): 222-229.

10. GA Borg (1982) Psychophysical bases of perceived exertion. Medicine and Science in Sports and Exercise 14(5): 377-381.

11. Rakobowchuk M, Tanguay S, Burgomaster KA, Howarth KR, Gibala MJ, et al. (2008) Sprint interval and traditional endurance training induce similar improvements in peripheral arterial stiffness and flowmediated dilation in healthy humans. American Journal of PhysiologyRegulatory, Integrative and Comparative Physiology 295(1): R236-R242.

12. Montuschi P, Barnes PJ, Roberts LJ (2004) Isoprostanes: Markers and mediators of oxidative stress. The FASEB Journal 18(15): 1791-1800.

13. Alessio HM (1993) Exercise-induced oxidative stress. Medicine and science in sports and exercise 25(2): 218-224.

14. Tauler P, Aguiló A, Gimeno I, Guix P, Tur JA, et al. (2004) Different effects of exercise tests on the antioxidant enzyme activities in lymphocytes and neutrophils. The Journal of nutritional biochemistry 15(8): 479484 .

15. Sinert R, Kohl L, Rainone T, Scalea T (1994) Exercise-induced rhabdomyolysis. Annals of emergency medicine 23(6): 1301-1306.

\section{Your next submission with Juniper Publishers} will reach you the below assets

- Quality Editorial service

- Swift Peer Review

- Reprints availability

- E-prints Service

- Manuscript Podcast for convenient understanding

- Global attainment for your research

- Manuscript accessibility in different formats ( Pdf, E-pub, Full Text, Audio)

- Unceasing customer service

Track the below URL for one-step submission https://juniperpublishers.com/online-submission.php 